\title{
Evaluation of Expression of the PTEN Gene, Oestrogen and Progesterone Receptors as Diagnostic and Predictive Factors in Endometrial Cancer
}

\author{
Dariusz Samulak • Patrycja Grosman-Dziewiszek • Magdalena M. Michalska • \\ Ewa Mojs • Katarzyna Samulak • Hanna Romanowicz • Beata Smolarz
}

Received: 4 October 2012 / Accepted: 30 July 2013 /Published online: 13 September 2013

(C) The Author(s) 2013. This article is published with open access at Springerlink.com

\begin{abstract}
Endometrial cancer belongs to the commonest malignancy in females after breast cancer, malignant neoplasm of female genitals in Europe and North America but there is still not significant improvement as far as the curability of this neoplasm is concerned, especially its advanced forms. That is why there is need to define new factors that could be not only diagnostic but also predictve factors. In present study we analyzed the mRNA PTEN expression by quantitative realtime polymerase chain reaction (Q-PCR) in 123 women of
\end{abstract}

D. Samulak

Cathedral of Mother's and Child's Health, Poznan University

of Medical Sciences, ul. Polna 33, 60-535 Poznań, Poland

D. Samulak • M. M. Michalska

Department of Obstetrics and Gynaecology, Regional Hospital

in Kalisz, ul. Toruńska 7, 62-800 Kalisz, Poland

D. Samulak

State Higher Vocational School in Kalisz, ul. Nowy Świat 4,

62-800 Kalisz, Poland

P. Grosman-Dziewiszek

Faculty and Institute of Histology and Embryology,

Academy of Medical Sciences in Wrocław, ul. Chałubińskiego 6a,

50-368 Wrocław, Poland

E. Mojs

Department of Clinical Psychology, Poznan University of Medical

Sciences, Poznań, Poland

K. Samulak

Student Scientific Society, University of Medical Sciences in Poznan, ul. Polna 33, 60-535 Poznań, Poland

H. Romanowicz $\cdot$ B. Smolarz $(\square)$

Department of Pathology, Laboratory of Molecular Genetics,

Institute of Polish Mothers Memorial Hospital, Rzgowska 281/289,

93-338 Lodz, Poland

e-mail: smolbea@wp.pl endometrial carcinoma and 14 women of control group. Moreover we assessed oestrogen (ER) and progesterone receptors (PgR) in all cases. We defined the correlation between expression of PTEN gene and receptors and between PTEN expression and maturity grade of cancer. Neoplasm advancement grade $\mathrm{G} 1$ was diagnosed in $82.11 \%$ of patients $(n=101)$, G2 in $9.76 \%$ of patients $(n=12)$ and $\mathrm{G} 3$ in $8.13 \%$ of patients $(n=10)$. Presence of ER and PgR and decreased expression of PTEN gene was found in majority of patients with endometrial cancer (79.12\% and $59.34 \%$ respectively) and the most numerous group was with weak expression of ER and strong expression of PgR. There was no statistically significant difference in gene expression depending on receptors expression nor maturity grade of cancer $(p>0.05)$. Evaluation of expression of PTEN gene may turn out to be a very useful tool aimed at qualifying patients for different therapies of endometrial cancer and at searching of new diagnostic and therapeutic methods of this cancer independently on its receptor status nor maturity grade of cancer.

Keywords Endometrial cancer - Oestrogen and progesterone receptors $\cdot$ PTEN gene $\cdot$ Predictive factor

\section{Introduction}

Endometrial cancer (EC) is the most frequent, after breast cancer, malignant neoplasm of female genitals in Europe and North America and the fourth among all malignant neoplasms in women, after breast cancer, lung cancer and large intestine cancer [1-3]. EC cancerogenesis is not fully recognized process regarding many risk factors. Prognostic factors commonly used to identification of endometrial cancer present an incomplete picture of the tumour biology of endometrial cancer [4]. Therefore, investigation of other prognostic factors 
is of special clinical relevance, particularly in view of the unexpectedly progressive course of the disease and frequent relapses in some cases. PTEN is the most frequently mutated gene identified yet in endometrial cancers [5, 6].

PTEN (Phosphatase and Tensin Homologue) is a supressor gene located in chromosome 10q23. It codes lipid and protein phosphatase (PTEN) and contributes to the control of the proliferation, differentiation and apoptosis process [7]. The PTEN tumor suppressor gene regulates the oncogenic phosphatidylinositol 3-kinase (PI3K) signaling pathway that is involved in carcinogenesis. Downstream of those two pathways is $A K T$, a serine-threonine kinase that is regulated by $P I 3 K$ and influences apoptosis and cell proliferation [7]. Alterations in the PTEN-PI3K-AKT pathways have been reported for hormone-related tumors among women, including breast, ovarian $[8,9]$ and endometrial $[5,6]$ cancers. Until now it has been found that PTEN mutations are the most frequent genetic changes in endometrial cancer of type I and occur in $25-83 \%$ of tumours, including tumours with microsatellite instability [10]. PTEN inactivation was described most frequently in early stages of endometrial cancer whilst in other types of neoplasms it occurs in their more advanced stages and is connected with cancer cells metastases [11]. Due to this fact, PTEN may be a good endometrial cancer marker, already in the early stage of its development $[12,13]$.

PTEN expression correlates negatively with neoplasm advancement grade. PTEN mutations, occurring in an early development stage of the tumour, result in lack of cell differentiation, which might be connected with a more aggressive neoplasm type [14, 15].

In light of substantial evidence that the progression of endometrial cancer can be associated with PTEN, it seems reason able to check a possible correlation between the expression of this gene and clinical status of endometrial cancer patients.

\section{Material and Methods}

\section{Patients}

Endometrium was obtained from 137 women who underwent hysterectomy with adnexectomy in the Gynaecological and Obstetric Clinical Hospital of the University of Medical Sciences in Poznan between 2004 and 2006. Tumour tissues were obtained from women with endometrial adenocarcinoma. Clinical data for the patients and histological data were registered. There were 123 women and their mean age was $60,6 \pm$ 10.0 years (range: $34-85$ years). Endometrium from agematched, cancer-free women $(n=14)$ served as control (the mean age 60,1 \pm 7.6 ). Endometrial carcinomas were classified according to the criteria of the International Federation of Gynecology and Obstetrics (FIGO). Histological typing and grading were done according to the $\mathrm{WHO}$ classification.
Before the surgery each patient underwent a subject examination, a gynaecological examination, an ultrasonographic examination by means of an intravaginal probe and preoperative laboratory tests. Moreover, a conscious written consent to operation and uptake of segments of the endometrium for the sake of scientific research was signed by every patient.

Tissue material obtained after the operation from each patient was divided into two parts. From one part wax blocks were created, and after that specimens for histopathological assessment dyed with hematoxilin and eosin $(\mathrm{H}+\mathrm{E})$. The other part of the material was frozen in $-80{ }^{\circ} \mathrm{C}$. The procedures, used in the study, were approved by the Ethical Committee of the Medical University of Poznań (Poland).

\section{Evaluation of ER and PR}

ER and PR status was determined by immunohistochemical method as part of the routine clinical practice. In this method ready antibodies Monoclonal Mouse Anti-Human Progesterone Receptor Clone PgR 636 and Monoclonal Mouse AntiHuman Oestrogen Receptor $\alpha$ Clone ER 1D5 were used. Using the immunohistochemical assay, tumors were classified as positive if more than $10 \%$ of the cells showed nuclear staining for the receptor. This information was received together with the characteristics of clinical material. Figure 1 shows the quality of immunohistochemical reactions.

\section{Quantitative Real-Time RT-PCR}

Samples were stored at $-80{ }^{\circ} \mathrm{C}$ until RNA preparation. In the frozen specimens, after isolating RNA (ribonucleic acid) and rewriting it into cDNA (complementary deoxyribonucleic acid) in the reverse transcription reaction, the expression level of the PTEN gene was assessed by means of the real-time PCR (polymerase chain reaction) method. RNeasy Mini Kit by Qiagen, a QuantiTect Reverse Transcription kit by Qiagen, TaqMan Array 96WellPlates Applied Biosystems with an appropriate set of primers for the examined gene were used.

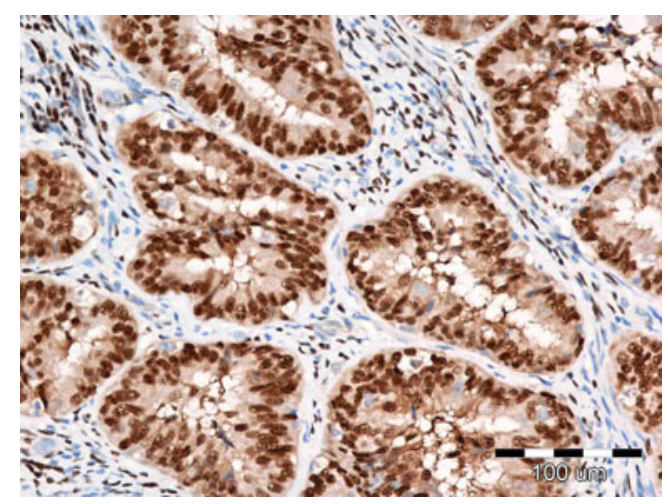

Fig. 1 ER expression in tumor tissue. IHC staining, original 
18S rRNA (ribosomal ribonucleic acid) constituted the internal control of the reaction. The reaction was repeated three times for each specimen. On the basis of the $\mathrm{Ct}$ value (threshold cycle - the number of reaction cycles after which fluorescence exceeds the defined threshold) of the examined gene and of the internal control gene the relative expression level of RNA was calculated according to the $\Delta \Delta \mathrm{Ct}$ (delta, delta $\mathrm{Ct}$ ) approximation method.

\section{Statistical Analysis}

The occurrence of statistically significant differences between expression of PTEN gene depending on receptors expression and on neoplasm maturity grade was checked by means of Kruskal-Wallis test.

The tests were carried out after obtaining a consent from the Bioethical Commission of the Academy of Medical Sciences of. Karol Marcinkowski in Poznań (Resolution number 240/04 from 05.02.2004).

The tests were carried out in the Patomorphological Laboratory of the Gynaecological and Obstetric Clinical Hospital of the University of Medical Sciences in Poznan and in the Faculty and Institute of Histology and Embryology of the Academy of Medical Sciences in Wrocław.

The statistical analysis was carried out in the Faculty and Institute of IT (informatics) and Statistics of the University of Medical Sciences in Poznań. For the sake of the analysis STATISTICA v. 8 was used, for multiple comparisons Kruskal-Wallis test was applied, U Mann-Whitney test was used to carry out the descriptive statistics for individual groups.

\section{Results}

In the final results of the histopathological examination neoplasm advancement grade G1 was diagnosed in $82.11 \%$ of patients with endometrial cancer $(n=101), \mathrm{G} 2$ in $9.76 \%$ of patients $(n=12)$ and $\mathrm{G} 3$ in $8.13 \%$ of patients $(n=10)$.

In 29 patients with endometrial cancer, it was impossible to mark receptors in the examined material. Out of the remaining 94, in 7 patients the lack of ER was detected and in 2 patients the lack of PgR. Expression of PTEN gene was possible to evaluate in 118 patients with endometrial cancer. Wherefore the number of patients in whom receptors and gene were marked together was 91. Taking these results into accound it was possible to divide patients with endometrial cancer into the following subgroups according to receptor expression intensification level. There were 17 patients in subgroup $\mathrm{ER}++/ \mathrm{PgR}+$ (strong expression of ER and strong expression of $\mathrm{PgR}$ ), 6 patients in subgroup ER++/PgR0 (strong expression of ER and weak or no expression of PgR), 44 patients in $\mathrm{ER}+/ \mathrm{PgR}+$ (weak expression of ER and strong expression of
PgR), 17 patients in ER+/PgR0 (weak expression of ER and weak or no expression of PgR), 5 in ER0/PgR + (no expression of ER and strong expression of PgR) and 2 patients in subgroup ER0/PgR0 (no expression of ER and weak or no expression of PgR). Dependecies of the presence of PTEN expression on the receptor status of patients with endometrial cancer are displayed in Table 1. In each receptor subgroup it was determined whether PTEN gene expression in the examined material was higher or lower than gene expression in the control group. Figure 2 shows summary of expression of PTEN gene depending on expression of ER and PgR.

By means of the Kruskal-Wallis test for multiple comparisons the occurrence of statistically significant differences between expression of PTEN gene in particular receptor subgroup was checked. No statistically significant difference in the field of the examined parameters was found.

Statistically significant differences between groups G1, G2 and G3 were examined in the event of $\Delta \triangle \mathrm{Ct}$ for gene PTEN. The assumed significance level was $p<0.05$ (Table 2).

No statistically significant difference in gene expression depending on neoplasm maturity grade was found.

\section{Discussion}

In this paper, apart from expression of PTEN and ER and PgR receptors in endometrial cancer, the following issues were examined: the occurrence of dependencies between intensification of PTEN expression and expression of receptors as well as the occurrence of statistically significant differences in gene expression depending on malignancy grade $\mathrm{G}$ of endometrial cancer.

Loss of PTEN expression is connected, through trail PI3K/ AKT, with loss of control of cell proliferation and apoptosis and with the promotion of neoplasm development [16] . Reduction of PTEN expression ensues most frequently through point mutations, loss of heterozygosity and promoter hypermethylation [17]. Somatic mutations of PTEN are common in endometrial cancer but occur mainly in type I cancer (in ca. 83\%) [10, 18-20]. Germinal mutations of PTEN occur in Crowden syndrome in $80 \%$ of instances [21]. Loss of heterozygosity occur in $40 \%$ of instances of endometrial cancer [22-25] and hypermethylation in circa $20 \%$, mainly in highly advanced cancers [26]. Matias-guiu et al. [23] report the occurrence of mutation and reduction of PTEN expression already during the hyperplasia stage. Similar data regarding PTEN inactivation, during the hyperplasia stage with or without atypy, occur in reports of Prat et al. [24] as well as Doll et al. [12]. Mutter et al. [11] found decreased expression in $75 \%$ of instances of the pre-cancer stage and in $95 \%$ of type I cancer and in $25 \%$ of type II cancer, which let them draw the following conclusion: disorders in PTEN expression are an early incidents in the development process of endometrioid 
Table 1 PTEN with altered expression in endometrial cancer patients $(n=91)$

\begin{tabular}{|c|c|c|c|c|c|c|}
\hline PTEN & $\begin{array}{l}\mathrm{ER}+/ \operatorname{PgR}+(n=17) \\
\text { Number }(\%)\end{array}$ & $\begin{array}{l}\text { ER++/PgR0 }(n=6) \\
\text { Number }(\%)\end{array}$ & $\begin{array}{l}\mathrm{ER}+/ \operatorname{PgR}+(n=44) \\
\text { Number }(\%)\end{array}$ & $\begin{array}{l}\text { ER+/PgR0 }(n=17) \\
\text { Number }(\%)\end{array}$ & $\begin{array}{l}\text { ER0/PgR + }(n=5) \\
\text { Number }(\%)\end{array}$ & $\begin{array}{l}\text { ER0/PgR0 }(n=2) \\
\text { Number (\%) }\end{array}$ \\
\hline Increased expression & $16(94.12)$ & $4(66.66)$ & $8(18.19)$ & $4(23.53)$ & $4(80)$ & $1(50)$ \\
\hline Decreased expression & $1(5.88)$ & $2(33.34)$ & $36(81.81)$ & $13(76.47)$ & $1(20)$ & $1(50)$ \\
\hline
\end{tabular}

endometrial cancer. Salvesen et al. [27] found the occurrence of promoter hypermethylation and decreased PTEN expression linked to this fact in 26 out of 138 patients (19\%) with endometrial cancer. Tests showed statistical significance regarding the occurrence of hypermethylation in advanced cancer stages. Latta et al. [28] found mutation of gene PTEN both in the normal endometrium exposed to oestrogens, pre-cancer stages as well as endometrial cancer. However, the percentage of patients with decreased expression of PTEN increased with the advancement of changes within the endometrium and amounted to $18-55 \%$ for pre-cancer stages and 26-80\% for cancer. Salvesen et al. [29] in their further research reported the presence of mutations in $54 \%$ of incidences of cancer and statistically significant dependency between the occurrence of mutations and young age of patients, low advancement according to FIGO, endometrioid cancer type, high maturity grade $\mathrm{G}$, the occurrence of microsatellite instability as well as poor prognosis. Also Mackay et al. [30] noticed in their research on 123 patients beneficial prognosis in instances of decreased PTEN expression in women with an advanced endometrial cancer. However, Erkanli et al. [31], finding more significant reduction of expression in cancers than in hyperplasia or normal endometrium, report the occurrence of statistically significant correlation between the reduction of expression and shorter survival time. Comparisons of expression degree of PTEN depending on neoplasm maturity were made by Inab et al. [32] as well as Kagan et al. [33]. They presented data which indicates a statistically significant dependency between maturity grade $\mathrm{G}$ and gene expression. Both testes showed more decreased expression in grade G1 and G2 than in G3. Moreover, Kagan found lower PTEN expression in specimens with positive expression of oestrogen and progesterone receptors. This difference was statistically significant. Sobczuk et al. [34] examining expression of this gene in 70 patients with cancer and 68 with normal endometrium found a significant difference in the reduction of PTEN expression between these two groups. Bogusiewicz et al. [35] examining among others PTEN expression in 45 women with primary endometrioid endometrial cancer found the reduction of PTEN level in $33 \%$ of incidences and lack of correlation between the reduction of expression of this gene and the occurrence of endometrial cancer.

In this paper decreased expression of gene PTEN was found in $59.34 \%$ of examined patients $(n=54)$, which
Fig. 2 Relationship between PTEN and ER and PgR expression

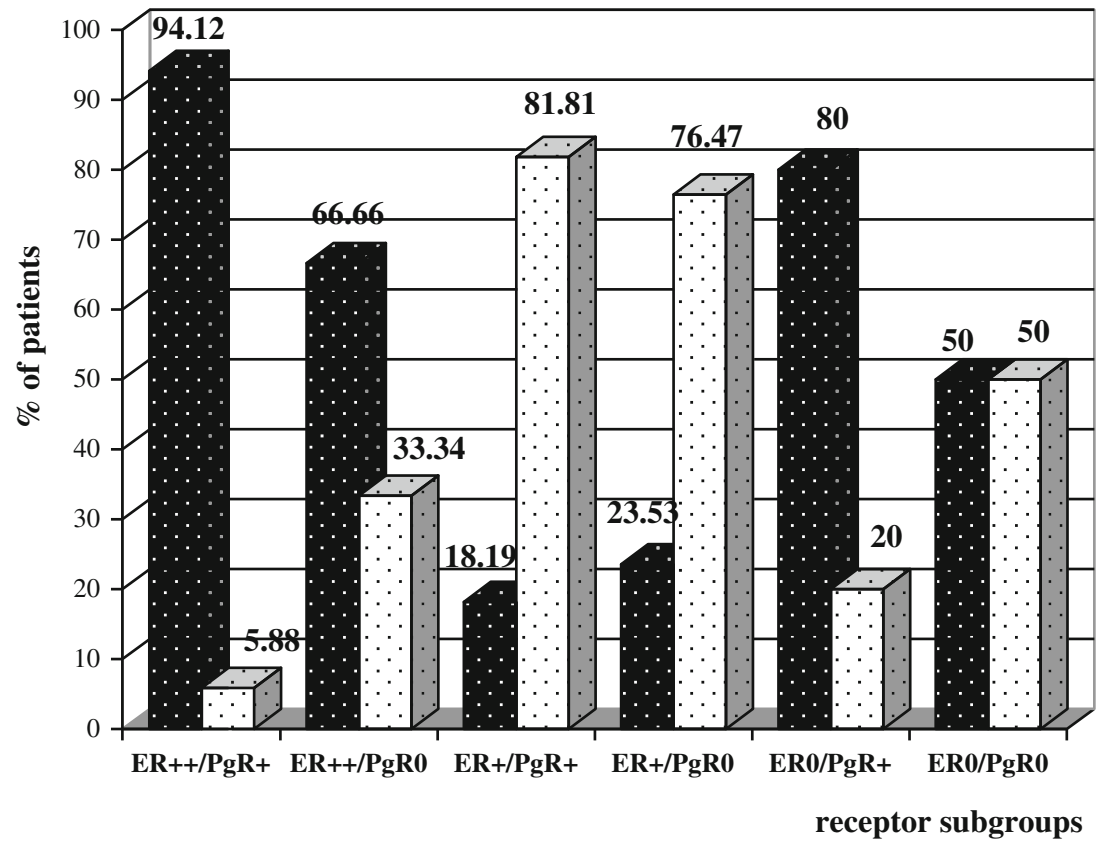

increased expression $\square$ decreased expression 
Table 2 Analysis of PTEN gene expression according to histological stage of endometrial cancer

Dependent: $\triangle \triangle \mathrm{Ct} P T E N$ Value $\mathrm{p}$ for multiple comparisons (bilateral); $\triangle \triangle \mathrm{Ct} P T E N$ Independent variable (grouping): maturity grade $\mathrm{G}$ Kruskal-Wallis: $\mathrm{H}(2, N=118)=5.422665 p=.0664$

\begin{tabular}{llll}
\cline { 2 - 4 } & G 1 & G 2 & G 3 \\
\hline G 1 & & 0.151903 & 0.855077 \\
G 2 & & & 0.076082 \\
G 3 & 0.151903 & & \\
\hline
\end{tabular}

confirms the thesis about the contribution of these gene to pathogenesis of endometrial cancer. However, a significant difference was noticed between the percentage of patients with overexpression and decreased expression of gene PTEN in individual receptor subgroups. Low expression was found in $76.47 \%$ of patients from subgroup ER+/PgR0 and in $81.81 \%$ of women from subgroup $\mathrm{ER}+/ \mathrm{PgR}+$. In subgroups $\mathrm{ER}++/ \mathrm{PgR}+, \mathrm{ER}++/ \mathrm{PgR} 0$ and $\mathrm{ER} 0 / \mathrm{PgR}+$ the amount of PTEN mRNA was decreased in $5.88 \%, 33.34 \%$ and $20 \%$ of incidences respectively, which in comparison with world reports is not without any meaning either. Subgroup ER0/ PgR0, in which $50 \%$ of patients had decreased expression, requires some explanations. However, due to the fact that this subgroup includes only 2 people, the results might not be reliable. Despite such a big percentage of patients with decreased expression of gene PTEN no statistically significant dependency regarding histological maturity grade has been found.

In research on the theory based on molecular rules of development of endometrial cancer attention has been drawn to a group of pharmaceuticals being mTOR inhibitors. mTOR (mammalian target of the rapamycin) is a protein (serine/threonine protein kinase) which constitutes a part of the trail regulating cell proliferation, growth and apoptosis (mTOR-AKT-PI3K-PTEN). In vitro tests showed sensitivity of endometrial cancer cells with PTEN inactivation to mTOR inhibitors. It happens because loss of PTEN leads to activation of many trails enhancing the activity of mTOR and at the same time uncontrolled cell growth [36]. Pharmaceuticals in this group include: temsirolimus (CCI-779), everolimus (RAD001) and deforolimus (AP23573) [10]. In tests carried out in 19 patients in an advanced endometrial cancer stage a partial response to treatment in 5 women (26\%) was found as well as inhibition of the development of the disease in 12 patients $(63 \%)$ [36, 37]. Other pharmaceuticals that are taken into account whenever PTEN expression is decreased include PI3K inhibitors (enzastaurin) and AKT inhibitors (triciribine) [10]. Due to this fact it seems justified to evaluate expression of PTEN and to begin a therapy based on this evaluation in patients suffering from endometrial cancer, especially in advanced incidences where other methods become ineffective or impossible to carry out.
Tests regarding expression of PTEN gene presented in this paper are in most cases compliant with the results obtained by other scientists and indicate their significant usefulness in the process of search for new endometrial cancer therapeutic methods as well as create new possibilities regarding use of PTEN markers as a predictive factor. However, it is a novelty to compare gene expression in hormone-dependent and hormone-independent groups. This gives a possibility to work out a treatment method individualized for each patient by means of e.g. mTOR inhibitors, PI3K inhibitors and AKT inhibitors as well as hormonotherapy.

\section{Conclusions}

1. Decreased expression of PTEN gene and expression of oestrogen and progesterone receptors occurs in the majority of patients with endometrial cancer.

2. Expression of PTEN gene and oestrogen and progesterone receptors is not dependent on each other.

3. Expression of PTEN gene is not dependent on the maturity grade of cancer.

4. Evaluation of expression of PTEN gene may turn out to be a very useful tool aimed at qualifying patients for different therapies of endometrial cancer and at searching of new diagnostic and therapeutic methods of this cancer, especially in relation with rare neoplasms and those with a poor prognosis, independently on their receptor status nor maturity grade of cancer.

Conflict of Interest Statement Authors declare that they have no conflict of interest.

Open Access This article is distributed under the terms of the Creative Commons Attribution License which permits any use, distribution, and reproduction in any medium, provided the original author(s) and the source are credited.

\section{References}

1. Ferlay J, Bray F, Pisani P, Parkin DM (2004) GLOBOCAN, 2002. Cancer incidence, mortality and prevalence worldwide. IARC CancerBase. IARC Press, Lyon

2. Jemal A, Murray T, Ward E, Samuels A, Tiwari RC, Ghafoor A et al (2005) Cancer statistics 2005. CA Cancer J Clin 55:10-30

3. Bray F, Loos AH, Oostindier M, Weiderpass E (2005) Geographic and temporal variations in cancer of the corpus uteri: incidence and mortality in pre- and postmenopausal women in Europe. Int J Cancer 117:123-131

4. Salvesen HB, Akslen LA (2002) Molecular pathogenesis and prognostic factors in endometrial carcinoma. APMIS 110:673-689

5. Hayes MP, Wang H, Espinal-Witter R, Douglas W, Solomon GJ, Baker SJ, Ellenson LH (2006) PIK3CA and PTEN mutations in uterine endometrioid carcinoma and complex atypical hyperplasia. Clin Cancer Res 12:5932-5935 
6. Oda K, Stokoe D, Taketani Y, McCormick F (2005) High frequency of coexistent mutations of PIK3CA and PTEN genes in endometrial carcinoma. Cancer Res 65:10669-10673

7. Blanco-Aparico C, Renner O, Leal J, Carnero A (2007) PTEN, more than AKT pathway. Carcicnogenesis 28:1379-1386

8. Stemke-Hale K, Gonzalez-Angulo AM, Lluch A, Neve RM, Kuo WL, Davies M, Carey M, Hu Z, Guan Y, Sahin A, Symmans WF, Pusztai L, Nolden LK, Horlings H, Berns K, Hung MC, van de Vijver MJ, Valero V, Gray JW, Bernards R, Mills GB, Hennessy BT (2008) An integrative genomic and proteomic analysis of PIK3CA, PTEN, and AKT mutations in breast cancer. Cancer Res 68:6084-6091

9. Levine DA, Bogomolniy F, Yee CJ, Lash A, Barakat RR, Borgen PI, Boyd J (2005) Frequent mutation of the PIK3CA gene in ovarian and breast cancers. Clin Cancer Res 11:2875-2878

10. Bansal N, Yendluri V, Wenham RM (2009) The molecular biology of endometrial cancers and the implications for pathogenesis, classification, and targeted therapies. Cancer Control 16:8-13

11. Mutter GL, Lin MC, Fitzerald JT, Kum JB, Baak JPA, Lees JA, Wenig LP, Eng C (2000) Altered PTEN expression as a diagnostic marker for the earliest endometrial precancers. J Natl Cancer Inst 92: 924-931

12. Doll A, Abal M, Rigau M, Monge M, Gonzalez M, Demajo S, Colas E, Llaurado M, Alazzouzi H, Planaguma J, Lohmann MA, Garcia J, Castellvi S, Ramon y Cajal J, Gil-Moreno A, Xercavins J, Alameda F, Reventos J (2008) Novel molecular profiles of endometria cancernew light through old windows. J Steroid Biochem Mol Biol 108: 221-229

13. Engelsen IB, Akslen L, Salvesen HB (2009) Biologic markers in endometrial cancer treatment. APMIS 117:693-707

14. Piekarski J (2005) Should we start routine assessment of expression of PTEN protein in patients with breast cancer? J Oncol 55:480-484

15. Maxwell GL, Risinger JI, Gumbs C, Shaw H, Bentley RC, Barrett JC, Berchuck A, Futreal PA et al (1998) Mutation of the PTEN tumor suppressor gene in endometrial hyperplasias. Cancer Res 58:2500 2503

16. Sarbassov D, Guertin DA, Ali SM, Sabatin M (2005) Phosphorylation and regulation of AKT/PKB by the Rictor-mTOR Complex. Science 304:1098-1101

17. Samarnthai N, Hall K, Yeh IT (2010) Molecular profiling of endometrial malignancies. Obstet Gynecol Int 2010:162363

18. Lax SF (2007) Molecular genetic changes in epithelial, stromal and mixed neoplasms of the endometrium. Pathology 39:46-54

19. Lax SF (2004) Molecular genetic pathways in various types of endometrial carcinoma: from a phenotypical to a molecularbased classification. Virchows Arch 444:213-223

20. Hecht JL, Mutter GL (2006) Molecular and pathologic aspects of endometrial carcinogenesis. J Clin Oncol 24:4783-4791

21. Pilarski R (2009) Cowden syndrome: a critical review of the clinical literature. J Genet Couns 18:13-27

22. Llobet D, Pallares J, Yeramian A, Santacana M, Eritja N, Velasco A, Dolcet X, Matias-Guiu X (2009) Molecular pathology of endometrial carcinoma: practical aspects from the diagnostic and therapeutic viewpoints. J Clin Pathol 62:777-785

23. Matias-guiu X, Catasus L, Bussaglia E, Lagarda H, Garcia A, Pons C, Muñoz J, Argüelles R, Machin P, Prat J (2001) Molecular pathology of endometrial hyperplasia and carcinoma. Hum Pathol 32:569-577

24. Prat J, Gallardo A, Cuatrecasas M, Catasús L (2007) Endometrial carcinoma: pathology and genetics. Pathology 39:72-87

25. Tashiro H, Blazes MS, Wu R, Cho KR, Bose S, Wang SI, Li J, Parsons R, Ellenson LH (1997) Mutations in PTEN are frequent in endometrial carcinoma but rare in other common gynecological malignancies. Cancer Res 57:3935-3940

26. Liu FS (2007) Molecular carcinogenesis of endometrial cancer. Taiwan J Obstet Gynecol 46:26-32

27. Salvesen HB, MacDonald N, Ryan A, Jacobs IJ, Lynch ED, Akslen LA, Das S (2001) PTEN methylation is associated with advanced stage and microsatellite instability in endometrial carcinoma. Int $\mathrm{J}$ Cancer 91:22-26

28. Latta E, Chapman WB (2002) PTEN mutations and evolving concepts in endometrial neoplasia. Curr Opin Obstet Gynecol 14:59-65

29. Salvesen HB, Stefansson I, Kretzschmar EI, Gruber P, MacDonald ND, Ryan A, Jacobs IJ, Akslen LA, Das S (2004) Significance of PTEN alterations in endometrial carcinoma: a population-based stud$\mathrm{y}$ of mutations, promoter methylation and PTEN protein expression. Int J Oncol 25:1615-1623

30. Mackay HJ, Gallinger S, Tsao MS, McLachlin CM, Tu D, Keiser K, Eisenhauer EA, Oza AM (2010) Prognostic value of microsatellite instability (MSI) and PTEN expression in women with endometrial cancer: results from studies of the NCIC Clinical Trials Group (NCIC CTG). Eur J Cancer 46:1365-1373

31. Erkanli S, Kayaselcuk F, Kuscu E, Bagis T, Bolat F, Haberal A, Demirhan B (2006) Expression of survivin, PTEN and p27 in normal, hyperplastic, and carcinomatous endometrium. Int J Gynecol Cancer 16:1412-1418

32. Inaba F, Kawamata H, Teramoto T, Fukasawa I, Inaba N, Fujimori $T$ (2005) PTEN and p53 abnormalities are indicative and predictive factors for endometrial carcinoma. Oncol Rep 13:17-24

33. Kagan J, Srivastava S (2005) Mitochondria as a target for early detection and diagnosis of cancer. Crit Rev Clin Lab Sci 42:453-472

34. Sobczuk A, Smolarz B, Romanowicz-Makowska H, Pertyński T (2006) MMAC/PTEN gene expression in endometrial cancer: RTPCR studies. Pol J Pathol 57:137-140

35. Bogusiewicz M, Semczuk A, Gogacz M, Skomra D, Jakowicki JA, Rechberger $T$ (2006) Lack of correlation between leptin receptor expression and $\mathrm{PI}-\mathrm{K} / \mathrm{Akt}$ signaling pathway proteins immunostaining in endometrioid-type endometrial carcinomas. Cancer Lett 238: $61-68$

36. Temkin SM, Fleming G (2009) Current treatment of metastatic endometrial cancer. Cancer Control 16:38-45

37. Gadducci A, Tana R, Cosio S, Fanucchi A, Genazzani AR (2008) Molecular target therapies in endometrial cancer: from the basic research to the clinic. Gynecol Endocrinol 24:239-249 